\title{
LA CELDA Y EL TALLER. EL PENAL DEL DUESO (SANTOÑA), UN ENSAYO DE COLONIA PENITENCIARIA EN LAS PRIMERAS DÉCADAS DEL SIGLO XX
}

\author{
Carmen Gil de Arriba \\ Departamento de Geografía, Urbanismo y Ordenación del Territorio. Universidad de Cantabria \\ carmen.gil@unican.es
}

\section{RESUMEN}

El establecimiento penal del Dueso nace en 1907 como primer ensayo, a escala española, de colonia penitenciaria interior, es decir implantada en la Península y conforme a los planteamientos reformistas de los penalistas más destacados de este período intersecular. Diversos obstáculos encontrados a lo largo de sus primeros años de construcción y funcionamiento hicieron que el grandioso proyecto arquitectónico, inicialmente aprobado para este espacio de reclusión, no llegara a desarrollarse en su totalidad, sufriendo numerosos cambios y transformaciones ya desde las primeras décadas del siglo XX. Este trabajo trata de adentrarse en los factores históricos y territoriales que explican el nacimiento de este espacio y sus lógicas de funcionamiento, como experimento de regeneración social, de control ideológico y de gestión de la fuerza de trabajo de los penados.

Palabras clave: espacios de reclusión, geografía penitenciaria, colonia penitenciaria, arquitectura penitenciaria, Santoña, reformismo, regeneracionismo, colonización interior.

\section{ABSTRACT}

The Dueso penitentiary was set up in 1907 , in an attempt on a Spanish scale at creating the first peninsular colony. It was established in the Peninsula and fitted in with the reformist approach of the most prominent Spanish criminalists at the change of the century.

Fecha de recepción: marzo 2013.

Fecha de aceptación: diciembre 2013. 
This remarkable architectural project, initially endorsed for this imprisonment space, never reached total development due to diverse obstacles faced throughout the first years of construction and operation. As a result, many changes and transformations were suffered in the first decades of the twentieth century. This paper deals with the historical and territorial factors which explain the origins of this space. The operational logic as a social regeneration project of ideological control and management of the convict workforce is also discussed at length.

Key words: imprisonment spaces, penitentiary geography, penal colony, penitentiary architecture, Santoña, reformism, Spanish regenerationism, inside colonization.

«La prisión para el hombre no es solamente un edificio dentro de cuyas paredes se le encierra; la prisión es aquel lugar techado o al aire libre donde por fuerza se le retiene, y por eso intenta fugarse cuando trabaja en los arsenales, en los caminos, o descuaja la tierra virgen de una apartada colonia penal.» Concepción Arenal: Las colonias penales de la Australia y la pena de deportación. Madrid, 1877.

\section{INTRODUCCIÓN, OBJETIVOS Y METODOLOGÍA}

El objetivo de este trabajo es reflexionar sobre el origen y evolución de lo que, a comienzos del siglo XX, fue el proyecto de construcción de la colonia penitenciaria del Dueso en Santoña, Cantabria, germen de la actual entidad funcional con más de un siglo de existencia, situada en el extremo Norte de la Península, en un área litoral y de marismas en la desembocadura al Cantábrico del río Asón, emplazamiento llamativo por su características físicas y paisajísticas (Figura 1). El período cronológico escogido es el de las primeras décadas de edificación y funcionamiento del establecimiento penitenciario, es decir desde el decreto de creación en 1907 hasta los años 20'.

El motivo de esta elección temática es porque entendemos que se trata de un caso singular y significativo, a escala española, de configuración de un espacio de reclusión, en cuya arquitectura pretendieron simbolizarse una serie de planteamientos ideológicos reformistas y regeneracionistas, gestados en el contexto nacional e internacional de la época. A la par, el modelo de colonia penal que se fue configurando trató de ser la expresión de unas determinadas estrategias de poder, disciplina y control que sobrepasaron ampliamente el ámbito local y regional.

Puede afirmarse, como señala P. Fraile (1998), que las cárceles tienen un valor singular al intentar adentrarse en la personalidad de los lugares, pese a que esta problemática suele ser eludida en los estudios urbanos, por lo que la existencia de una cárcel o de un centro penitenciario conlleva de valoración negativa o de estigmatización de los lugares en los que tales edificios se asientan.

La localización de los espacios carcelarios guarda lógicas históricas y territoriales. El pretender adentrarse en el estudio de estas lógicas lleva a tener en cuenta los distintos factores (sociales, culturales, políticos, legislativos, medioambientales o relacionados con el paisaje y el entorno físico) que, a lo largo del tiempo, han condicionado la implantación 
Figura 1

SANTOÑA EN 1812, CARTA NÁUTICA: SU ASPECTO CASI INSULAR QUE CONSERVA UN SIGLO MÁS TARDE

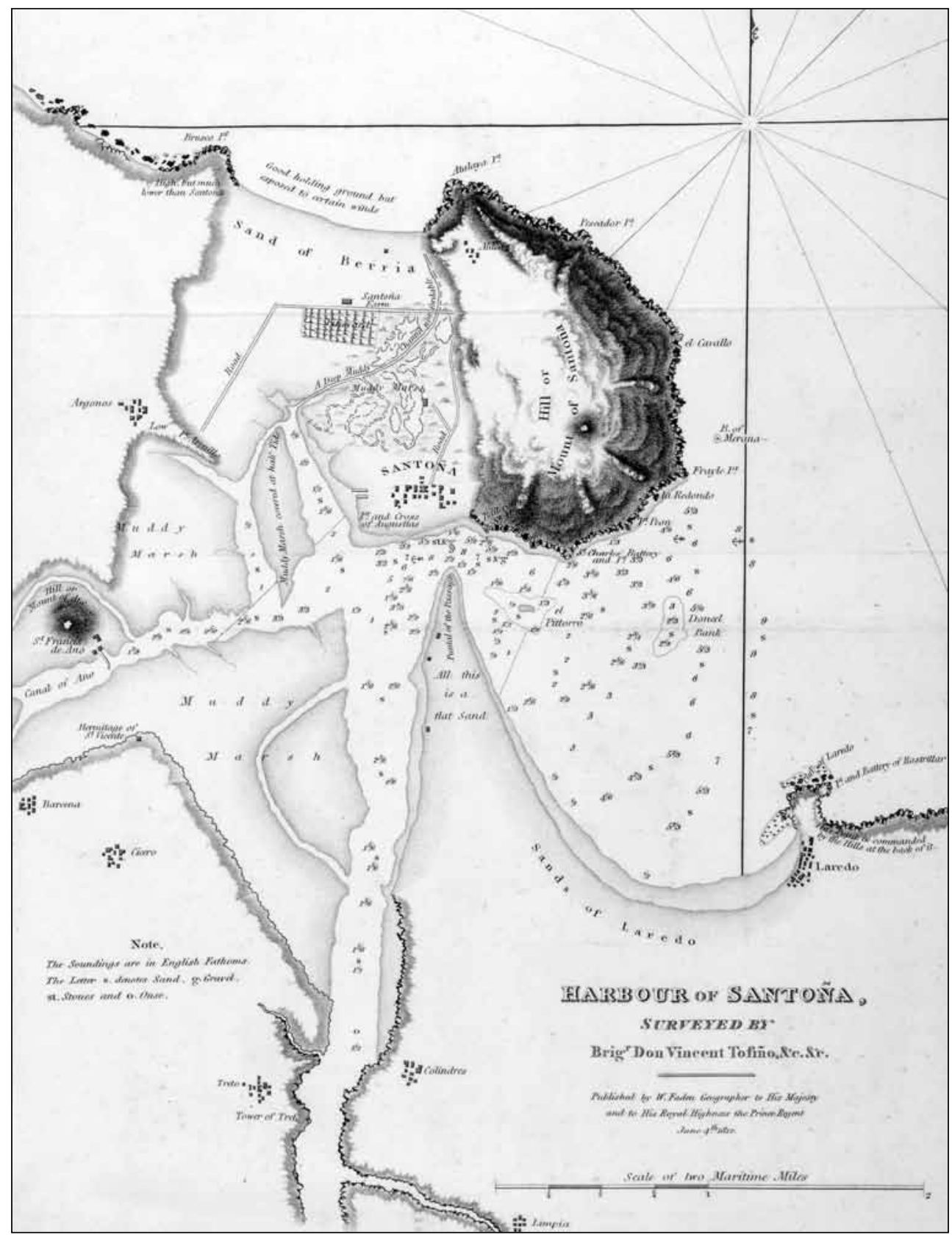

Fuente : Harbour of Santoña, surveyed by Brig ${ }^{\mathrm{r}}$ Vicente Tofiño. España Marítima or Spanish Coasting Pilot, Lam. 6. 27x35 cm. Museo Naval de Madrid, Colección: MN. Signatura: A-10.022-6. 
y la permanencia de un establecimiento penitenciario en un lugar determinado. Apoyándonos en una expresión utilizada por Fraile, se trata de sondear la «lógica locacional» del penal del Dueso en su contexto socioespacial, es decir, la España y la Santoña del período intersecular. Consideramos que esta territorialidad de los espacios de reclusión penal, construida socialmente, se manifiesta en los usos y funcionalidad asignados a los lugares y que implican, entre otros aspectos, la primacía de determinadas opciones y de ciertos grupos e intereses, a la vez que el mantenimiento del orden social establecido. De tal modo, este trabajo es una tentativa de análisis de los procesos de construcción y apropiación de un espacio penitenciario, desde la óptica de la geografía social y por lo tanto de los diversos sectores implicados.

El método de investigación se basa en la interrogación de fuentes históricas escritas, como la Gaceta de Madrid, el Diario oficial del Ministerio de la Guerra o el Memorial de Ingenieros del Ejército (1881-1936), así como de periódicos y revistas de tirada nacional publicados en las décadas iniciales del siglo $\mathrm{XX}^{1}$. Igualmente dedicamos atención a los proyectos elaborados por el ingeniero militar Lorenzo de la Tejera para la construcción del complejo penitenciario. Asimismo utilizamos fuentes gráficas, entre las que sobresalen los planos de localización y una colección de fotografías y tarjetas postales de los primeros años de actividad del Dueso ${ }^{2}$. Por lo demás, para la fundamentación teórica de nuestro trabajo, nos apoyamos en la bibliografía que aparece citada a lo largo del texto, destacando los trabajos de Fraile, Garland, Ignatieff, Melossi y Pavarini.

\section{COLONIAS PENALES Y PLANTEAMIENTOS DE REFORMA EN MATERIA PENITENCIARIA EN LA ESPAÑA DE ENTRESIGLOS}

La locución «colonia penitenciaria» sugiere un asentamiento alejado de otros núcleos habitados y aislado socialmente, espacio de reclusión donde los presos realizan trabajos forzados. Inglaterra, Francia o Rusia han utilizado históricamente este tipo de prácticas, los dos primeros países en varias de sus posesiones de Ultramar, el segundo en las colonias penales de Siberia y de la isla de Sajalín (Chejov, 2005). En el siglo XVIII, en los casos británico y francés, el confinamiento de proscritos en territorios distantes de la metrópoli tenía por finalidad tanto el ejercicio de la represión o el castigo como el de extender el proceso de colonización, incrementando la población y la mano de obra de las colonias. Como es sabido, Australia fue una gran colonia penal desde finales del XVIII hasta mediados del XIX. Uno de estos destinos fue Botany Bay en la costa sudeste australiana, al Sur de la ciudad de Sidney. En esta ensenada se instaló una de las primeras colonias penitenciarias, a finales del XVIII, con una existencia dilatada de casi cien años (Frost, 2011).

Un siglo más tarde del nacimiento de esta colonia penal australiana, en 1875, cuando en España se estaba produciendo un trascendental debate sobre la necesidad de reforma del sistema penitenciario y los métodos para la corrección/rehabilitación de los penados (Lario, 2004), la Real Academia de Ciencias Morales y Políticas propuso como tema, para el con-

1 Entre ellos El País, El Siglo futuro, El Liberal, La Época, Madrid Científico, La Correspondencia de España, El Imparcial, La Correspondencia Militar, etc.

2 Proporcionadas por el profesor de la Universidad de Cantabria José María Sierra y por Carlos Fonfría, Manuel Silva y Pedro Martín, director y funcionarios del centro penitenciario. 
curso ordinario de aquel año, una reflexión sobre si «¿Convendría establecer en las islas del Golfo de Guinea ó en las Marianas unas colonias penitenciarias como las inglesas de Botany Bay?». Tal idea de imitar el ejemplo de las colonias penitenciarias australianas, planteada en el último cuarto del XIX, cuando hacía ya más de dos décadas que el Reino Unido había empezado a desmontar el modelo, es muestra de las vacilaciones y del retraso en la puesta en práctica de reformas en España con respecto a otros países. Así, en contra de estos planteamientos de destierro de los reos se manifestó Concepción Arenal en su estudio sobre Las colonias penales de la Australia y la pena de deportación. Este trabajo fue presentado de manera anónima, al igual que el resto de obras participantes en el concurso y recibió el primer premio de la institución convocante ${ }^{3}$.

De los otros cuatro trabajos propuestos para el concurso convocado en 1875 por la Real Academia de Ciencias Morales y Políticas, el del penalista Pedro Armengol y Cornet fue galardonado con el primer accésit ${ }^{4}$. Este segundo autor también daba una respuesta negativa a la cuestión formulada, si bien sugiriendo la creación de un establecimiento penitenciario en las Islas Canarias, aunque sin precisar exactamente dónde. En concreto, Armengol señala: «si se quiere apartar á personas que por sus ideas, ó sus planes, ó sus actos, son peligrosas para el orden público y no hay recursos para plantear la colonia ó la penitenciaría, establézcase en las islas Canarias un depósito; pero donde reine la moralidad, el aseo, la disciplina, la higiene, y con una vigilancia regular y un buen personal directivo, se lograría el mismo objeto, sin la mortalidad consiguiente á los climas tropicales» (opus cit.: 109-110). Retenemos estos planteamientos ya que resultan muy semejantes a los que, treinta años más tarde, inspirarían la creación de la colonia penitenciaria del Dueso.

Por último, el segundo accésit lo recibió la memoria de Francisco Lastres y Juiz ${ }^{5}$, quien de los tres merecedores de premio era el único que argumentaba a favor del establecimiento de colonias penitenciarias en el Golfo de Guinea y en las Marianas, si bien teniendo en cuenta las propuestas del sistema progresivo de Walter Crofton, al que nos referiremos posteriormente en el caso del Dueso. Escribe Lastres: «Ya dijimos que la colonización penitenciaria no consistía en enviar los delincuentes á las islas sin preparación ninguna, porque además de ser inhumano, se originarían conflictos á las provincias apartadas de la Metrópoli; pero estos peligros desaparecen, cuando se somete á los penados á un régimen cuyo último término sea la colonización» (opus cit.: 63-64).

Para este período de entre siglos, son también de recordar los trabajos de otros autores, siendo uno de los más notorios Rafael Salillas y Panzano, médico y destacado alentador de los estudios de criminología en nuestro país ${ }^{6}$, en la línea de los italianos Cesare Lombroso

3 A continuación sería publicado en Madrid: Imprenta y librería de Eduardo Martínez (Sucesor de Escribano), 1877, 99 p. En él, Concepción Arenal acuña la famosa frase: «Decidme cuál es el sistema penitenciario de un pueblo y os diré cuál es su justicia».

4 Publicado en 1878, Madrid: Imprenta y librería de Eduardo Martínez (Sucesor de Escribano), 110 p. Pedro Armengol fue autor de las obras tituladas La cárcel modelo de Madrid y la ciencia penitenciaria. Imprenta de Jaime Jepús Proviralta, 1876, 278 p. y La nueva cárcel de Barcelona. J. Jepús, 1888, 58 p.

5 Publicada con el título de La colonización penitenciaria de las Marianas y Fernando Póo. Madrid: Imprenta y librería de Eduardo Martínez (Sucesor de Escribano), 1878, 68 p.

6 Fue uno de los promotores de la Escuela de Criminología, creada por Real decreto de 12/3/1903 e instalada en la prisión Celular de Madrid, donde empieza a funcionar en enero de 1906. Salillas fue director de dicha Escuela desde 1906 hasta su fallecimiento en 1923. 
y Enrico Ferri, autor de Sociología criminal (1884). Salillas ocupó los cargos de Inspector de servicios sanitarios de Prisiones y de Secretario general del Consejo Penitenciario. A la par que estos puestos oficiales, desarrolló una amplia producción escrita con afán modernizador y de reforma, como los artículos sobre la vida penal en España publicados en el diario matutino El Liberal de Madrid $^{7}$ o el libro titulado La vida penal en España, aparecido en 1888 y reseñado en el vespertino La Época de 12 de mayo de dicho año. Más tarde, ya a comienzos del siglo XX, dirigió la Revista penitenciaria (1904-1908) ${ }^{8}$, para la que confeccionó una serie de artículos sobre las causas sociales de la delincuencia. En 1906, no sin salvar obstáculos corporativos, fue nombrado director de la prisión Celular ó Modelo de Madrid.

Salillas, defensor de las ideas de reforma penitenciaria, fue también, como diremos más adelante, uno de los principales impulsores del proyecto de colonia penitenciaria del Dueso elaborado por el militar Lorenzo de la Tejera ${ }^{9}$, considerándola «obra colosal», «la más grande de cuantas hemos emprendido», a partir de la cual «se le ganarán al mar cinco millones y medio de metros cuadrados de marismas, valuados en muchos millones de pesetas, bastantes para el pago de las obras y dejar un cuantiosísimo remanente» (en el diario republicano El País de 5/5/1909, retomando las palabras pronunciadas por el propio Salillas en una interpelación planteada en el Senado).

Contemporáneo de Salillas fue el jurista Fernando Cadalso, con obras como El anarquismo y los medios de represión (Madrid, 1896) ó La pena de deportación y la colonización por penados (Madrid, 1895). En su libro de 1893 sobre Estudios penitenciarios, Cadalso se mostraba partidario de la creación de colonias penales, tanto en la Península como en el resto de posesiones españolas (Pérez García, 2002), para cuya construcción fuera utilizado el trabajo de los penados, quienes además se encargarían de cultivar campos, repoblar montes y abrir nuevas vías de comunicación ${ }^{10}$.

Cadalso fue Inspector general de Prisiones y director de la Revista de las prisiones, de carácter corporativo, que empezó a publicarse a inicios de la última década del XIX (18931909), con el subtítulo de «periódico de doctrina y legislación penitenciarias». Otros de sus puestos fueron el de vocal de la Junta de Prisiones y director de la prisión Celular de Madrid, cargo este último que ocupó antes del nombramiento de Salillas. Durante los primeros momentos de la dictadura de Primo de Rivera, en los meses de septiembre a diciembre de 1923, llegó a ser ministro de Gracia y Justicia ${ }^{11}$.

7 Entre ellos, los fechados el 15/3/1886, 3/5/1886, 20/11/1886, 4/7/1887, 25/1/1892, 3/2/1892, etc.

8 Órgano oficial del Consejo Penitenciario y homónima de la francesa Revue pénitentiaire et de droit pénal, creada en 1877 por la Société Générale des Prisons et de Législation Criminelle.

9 No en vano, él mismo, Rafael Salillas, era hijo de militar, hecho que recuerda en varios de sus escritos.

10 En la Revista de Obras Públicas $\mathrm{n}^{\circ} 5$ y n ${ }^{\circ} 9$ de 1853 se publican dos artículos referidos a la aplicación a las obras públicas de los confinados en presidios.

11 Desde estas fechas, coincidiendo con la muerte de Salillas que se produjo en mayo de 1923 y el inicio de la dictadura de Primo, la Escuela de Criminología empezó a languidecer, al tiempo que Fernando Cadalso accede a su dirección; en 1926 se suprime el presupuesto de la Escuela, por lo que ésta queda sin financiación. Su labor no sería retomada hasta la II República con el Instituto de Estudios Penales (cf. Mundo Gráfico, 1/3/1933 y La Libertad, 21/5/1935). 
También en esta etapa finisecular, el abogado y catedrático de Derecho penal y mercantil de la Universidad de Madrid, Luis Silvela, publica algunas de sus obras más conocidas ${ }^{12}$. En 1894, ingresa como miembro de la Real Academia de Ciencias Morales y Políticas, con un discurso leído el día 8 de abril de dicho año ${ }^{13}$. En él Silvela hace una revisión crítica de las teorías de Bentham ${ }^{14}$.

Asimismo, es necesario tener presente a Constancio Bernaldo de Quirós, autor de Las nuevas teorías de la criminalidad (1898) y La mala vida en Madrid (1901) ${ }^{15}$, lo mismo que a Pedro Dorado Montero, ambos vinculados a Francisco Giner de los Ríos y a la Institución Libre de Enseñanza.

Esta sucesión de argumentaciones diversas y de trabajos teóricos fue creando un considerable ámbito de reflexión, a partir del último cuarto del siglo XIX, coincidiendo con el Sexenio democrático y los primeros años de la Restauración borbónica (Burillo, 2011). Ya a inicios del siglo XX, este conjunto de ideas de reforma influiría en las transformaciones materiales que, de forma aún lenta y limitada, comenzaron a ser acometidas en el sistema penitenciario español. De modo más concreto, dicho corpus teórico reformista se vería reflejado en el proyecto de creación de la colonia penitenciaria del Dueso, que trató de levantarse como ejemplo modélico de estas concepciones.

Ciertamente, el concepto de «colonia penitenciaria interior» de finales del siglo XIX y comienzos del XX implicaba la redención del preso mediante el trabajo, lo que para llevarse a cabo suponía la adaptación a la Península de un modelo experimentado con anterioridad en los penales africanos, particularmente en el de Ceuta, como veremos más adelante.

A su vez, en el mismo año en el que se publica el decreto de creación de la colonia penitenciaria del Dueso, es decir en 1907, José Alijo Luque, funcionario de Prisiones ${ }^{16}$, escribe un artículo que resulta esclarecedor, en la Revista penitenciaria ${ }^{17}$ dirigida a la sazón por Rafael Salillas. En él retoma los planteamientos de la llamada «colonización interior», vigentes en aquellos momentos a partir del pensamiento regeneracionista y más en concreto, de un proyecto de ley presentado ese mismo año ${ }^{18}$, para aplicarlos, de manera específica, a

12 El Derecho penal: estudiado en principios y en la legislación vigente en España. Madrid: Imprenta de M.G. Hernández, 1874-1878, 2 vols.; El Código penal y el sentido común, Madrid: Imprenta de Manuel G. Hernández, 1886.

13 Madrid: Imp. de los Hijos de M.G. Hernández, 91 p.

14 Dice Silvela (opus cit.: 46): «ningún autor extranjero ha ejercido en España la influencia de Bentham desde 1820 á 1845» y prosigue explicando que el primer trabajo de exposición de la doctrina benthamista en España fue el de Jacobo Villanova y Jordán, titulado Cárceles y presidios: aplicación de la panóptica de Jeremías Bentham a las cárceles y casas de corrección de España, aparecido en 1834. En los años siguientes vinieron otros trabajos de traducción como los de Baltasar Anduaga y Espinosa (1841-1843).

15 Publicadas, respectivamente, en Madrid: Hijos de Reus, 357 p. y Madrid: B. Rodriguez Serra, 363 p.

16 Alijo escribe en la revista La América (Madrid) en los años 70' del siglo XIX y más tarde lo haría también en la Revista de las prisiones. Había sido nombrado administrador del penal de Ceuta en 1888, al reformarse la organización del personal de establecimientos penales, por virtud del Real decreto de 23/6/1881. En los años siguientes sería administrador del penal de Burgos, de la cárcel de Cádiz, del penal de Granada y del de Valencia.

17 «La colonización interior y la colonización penitenciaria», Revista penitenciaria, 1907, vol. 4, p. 548-557.

18 El 28 de mayo este año de 1907 (Gaceta de Madrid, 29/5/1907), el entonces ministro de Fomento, Augusto González Besada, presenta a las Cortes para su debate el proyecto de ley de colonización interior, que, mediante la creación de colonias agrícolas o industriales, pretendían reactivar terrenos baldíos y recuperar la mano de obra perdida en numerosas zonas del país, corrigiendo las desigualdades territoriales, demográficas y económicas. El 14/12/1907 se publica en la Gaceta de Madrid el decreto aprobatorio del reglamento provisional para la ejecución de la llamada Ley de colonización y repoblación interior. 


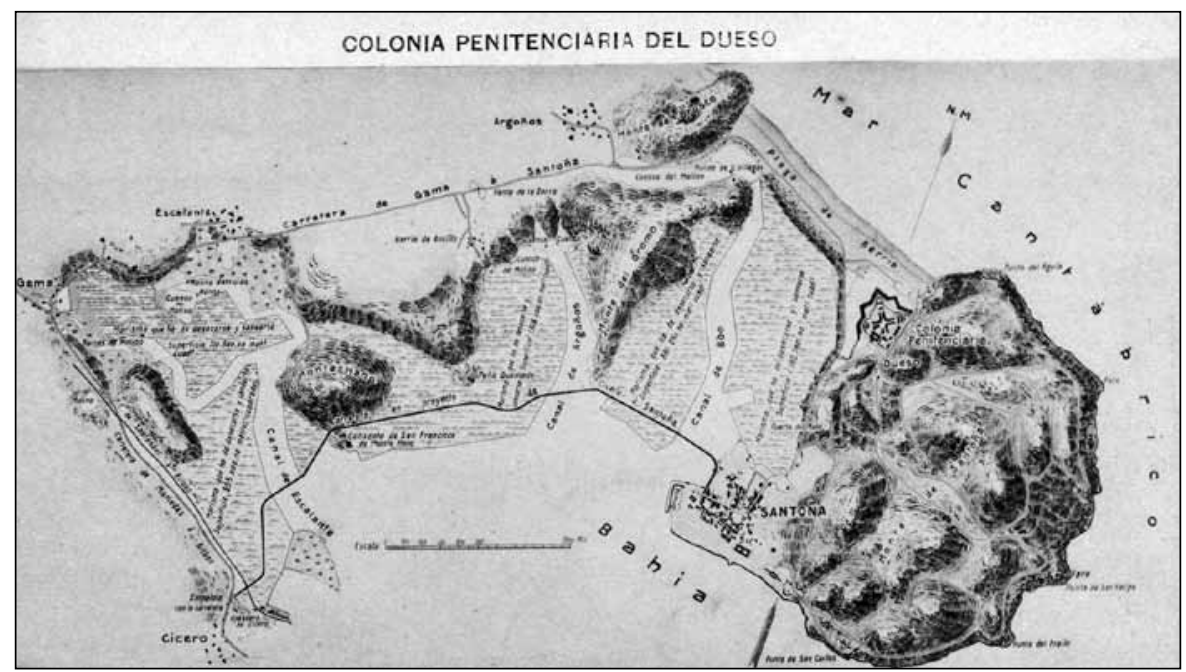

Fuente: Lorenzo de la Tejera: Algunas ideas sobre arquitectura e ingeniería penitenciarias: la colonia penitenciaria del Dueso. Memoria presentada al primer Congreso Científico celebrado por la Asociación Española para el progreso de las Ciencias en Zaragoza, octubre de 1908. 16 p. y 4 lam.

lo que habría de ser la «colonización agrícola penitenciaria», de la que la nueva prisión de Santoña trató de ser un prototipo (Figura 2). Dice Alijo en su artículo (1907:556): «Seguramente Santoña, [...], no será, si el programa se cumple, la menor beneficiada en ese ensayo, que le permitirá sanear muchas hectáreas de marismas, ponerlas en cultivo y realizar obras de comunicación suficientes á cambiar la vida de aquella villa, transformándola en pueblo agrícola, próspero y rico, y, sin duda alguna, en un paraje encantador, que buscarán los amantes de la Naturaleza espléndida y cuantos por sport y recreo ansían y buscan una playa cómoda donde pasar las estaciones estivales».

El mismo Salillas había venido defendiendo estos planteamientos de gestión de la fuerza de trabajo de los penados y su posibilidad de aplicación en materia de reforma penitenciaria $^{19}$. De hecho, las ideas de aunar ambos propósitos despertaron apasionados debates, con posturas a favor y en contra, como se muestra en el texto titulado «Colonización agrícola penitenciaria», publicado en la sección «La agricultura moderna» del periódico El Imparcial, de 3/8/1907 y cuyos argumentos, opuestos a la colonización penitenciaria interior, Alijo trata de rebatir en su citado artículo.

Por otra parte, todo este proceso guarda relación con una paulatina reformulación y modernización de las tácticas de autoridad, de control social y de orden público en la España de entre siglos. De manera que en el entorno carcelario, la inactividad y el hacinamiento indiscriminado de los presos, antaño predominantes, empezarían poco a poco a verse modi-

19 Así, El Imparcial de 29/1/1892 recoge el anuncio de la conferencia pronunciada, ese mismo día, por Salillas en el Ateneo de Madrid sobre el tema «La colonización de España y el problema penal». 
ficados como medios de represión y castigo. Se pasa así, paulatinamente, a la posibilidad individual de redención y rehabilitación mediante el trabajo dentro del propio entorno penitenciario. Aunque eso sí, en unos espacios acotados, con unas obligaciones impuestas y manteniendo una vigilancia y un control estrictos y permanentes.

\section{LA CREACIÓN DE LA COLONIA PENITENCIARIA DEL DUESO Y LA ELECCIÓN DEL SITIO DE SANTOÑA}

Además del contexto ideológico y político en el que se desenvuelve la creación de lo que, a principios del siglo XX, sería un nuevo centro de reclusión conforme al original modelo de colonia penal, es necesario tener en cuenta las cualidades del entorno espacial designado para la instalación, así como los factores que influyeron en la elección de este lugar en concreto.

Como hemos venido anticipando, el nuevo establecimiento penitenciario que empezó a levantarse en el municipio de Santoña a finales de la primera década del siglo pasado, en el barrio del Dueso del que toma su nombre, trató de ser un ejemplo ideal de reforma en materia de arquitectura y de organización penitenciaria en España; pretensiones éstas que sin embargo resultarían en buena medida utópicas, puesto que, como veremos más adelante, quedarían en parte desaprovechadas, al cumplirse tan sólo una fracción reducida de las previsiones originarias.

\section{III.1. El emplazamiento santoñés: sus condicionantes físicos e históricos}

Los terrenos elegidos para la construcción del penal modelo se hallaban en el centroNorte de la Península, a 48 kilómetros al Este de Santander y a 71 al Oeste de Bilbao, enclavados en una zona litoral, de estuario y de humedales salobres. Ello implicaba un cierto aislamiento y una serie de limitaciones en cuanto a comunicaciones, lo que unido a un ambiente marítimo, abierto y bien ventilado, representaba, según las concepciones higienistas de la época, unas condiciones propicias para la instalación de una colonia penitenciaria, entre cuyos objetivos se hallaba el trabajo al aire libre de una parte de los condenados.

A principios del siglo XX, el camino de acceso a este peculiar espacio, casi insular, que constituye el municipio de Santoña discurría únicamente a través del estrecho istmo arenoso de Berria, cuya anchura media no superaba los doscientos metros, teniendo que bordear la marisma por los municipios de Escalante y Argoños. Desde mediados del XIX, la carretera que enlazaba Santoña y Bárcena de Cicero estaba considerada como de segundo orden ${ }^{20}$. En 1894, la citada calzada se incluye, para su mejora, dentro de un plan general de carreteras (Gaceta de Madrid de 1/1/1894). Por su parte, la carretera llamada «de los puentes», actual CA 241, sobre los canales de Boo, Escalante y Argoños, no se construiría hasta la primera mitad de los años 20' del pasado siglo, atravesando el estuario en dirección nordestesuroeste. En cuanto a la línea férrea Santander-Bilbao, con parada en la estación de Gama dentro del municipio de Bárcena de Cicero, a unos 15 kilómetros de Santoña, su inauguración se produjo en 1896.

20 Declarada como tal por el Real decreto de 20 de febrero de 1861, publicado en la Gaceta de Madrid de $26 / 02 / 1861$. 
A pesar de estas difíciles condiciones de acceso, en los primeros años de construcción del Dueso, en torno a 1910, el núcleo de Santoña contaba con 6.390 habitantes de derecho y 1.083 hogares. El municipio había experimentado un crecimiento demográfico considerable, de nada menos que el 45,5\% con respecto a la población censada en 1900 (Figura 3). No obstante, con una superficie total de tan sólo $11 \mathrm{~km}^{2}$, se desenvolvía en un territorio exiguo y constreñido entre el peñón al Nordeste, que también le servía de abrigo y las marismas al Suroeste.

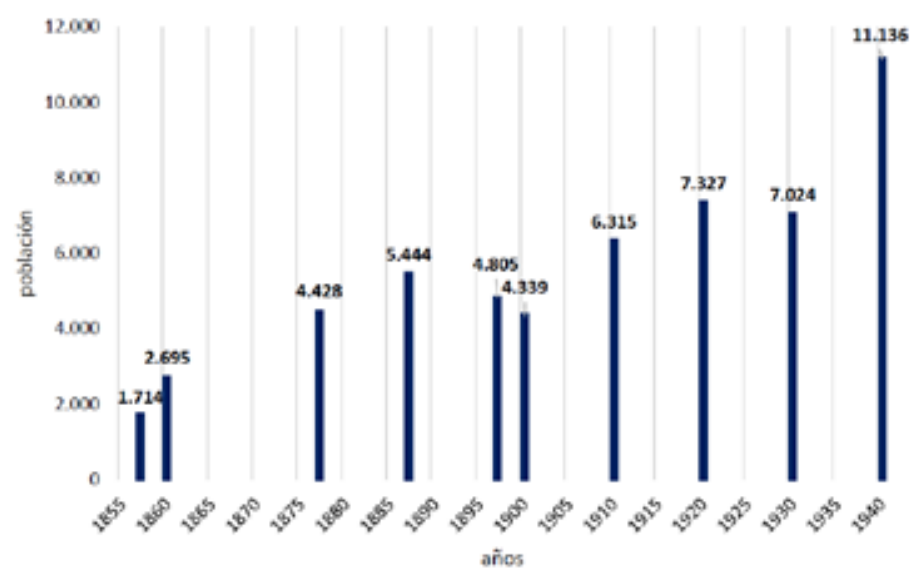

Fuente: cifras y censos, series históricas de población. INE; elaboración propia.

Desde el punto de vista socioeconómico, la villa empezaba a alcanzar un desarrollo imponente de la actividad pesquera. Esta situación pronto daría pie para el avance de la industria conservera, llegando a destacar por la fabricación de anchoas en salazón ${ }^{21}$ (Ansola, 2000), lo que explica este rápido crecimiento demográfico. El puerto también mantenía una labor comercial notable. El 12 de junio de 1907, se publicó la Real orden de ampliación de la Aduana de Santoña para la importación de pescado fresco o en salazón, a instancia de varios fabricantes de conservas, que por el incremento de la producción precisaban importar pescado del extranjero, ya que el local no era suficiente.

Asimismo, Santoña, por su ubicación, su bahía y sus fondeaderos, había venido siendo un respetable puesto militar desde el siglo XVIII (Palacio, 1998). Esta posición estratégica adquirió importancia durante la presencia napoleónica. Las tropas francesas que permanecieron en la plaza entre 1808 y 1814 iniciaron la construcción de un entramado de fortificaciones defensivas costeras y terrestres, entre las que sobresalen los fuertes del Mazo, San Martín y San Carlos, así como varias baterías y polvorines. Hoy en día, los restos de toda esta

21 Como se recoge en el diario municipal de Noticias de Santoña, $\mathrm{n}^{\circ} 27$, de mayo de 2007 , entre junio de 1906 y junio de 1907 se había sobrepasado la elaboración de más de un millón de kilos de anchoas, a cargo sobre todo de fabricantes italianos que, a su vez, establecieron contactos con comerciantes y distribuidores catalanes y que progresivamente, a lo largo de las tres primeras décadas del siglo XX, se fueron instalando en la villa. 
arquitectura militar decimonónica constituyen un rico patrimonio y en su momento llegaron a valerle a la localidad, en los ambientes castrenses de la época, la denominación de «Gibraltar del Norte»22 (Palacio, 2004).

No obstante, a finales del XIX, el papel militar de Santoña había descendido notoriamente con respecto a épocas pasadas (Palacio, 2001). Los progresos en navegación y en sistemas defensivos habían ocasionado estos cambios y esta pérdida de importancia. Por ello, hacia 1885, la plaza militar de Santoña había pasado a ser de tercera clase. En su informe sobre la «Importancia militar actual de la plaza y puerto de Santoña», publicado en la revista Memorial de Ingenieros del Ejército, $\mathrm{n}^{\circ} 1$ y 2, correspondiente a los meses de enero y febrero de 1893, el propio Lorenzo de la Tejera, quien por aquel entonces se hallaba realizando un estudio sobre la mejora de las defensas del litoral marítimo español, desde Rosas a Fuenterrabía, explica sus puntos de vista, concluyendo que «hoy no reune (sic) las condiciones necesarias para servir de eje de operaciones á un cuerpo de ejército», al tiempo que «su puerto no satisface, ni mucho menos, á las condiciones que uno militar debe reunir» ${ }^{23}$.

Así las cosas, en 1901 se eliminó la Comandancia de Ingenieros militares con sede en la villa (Palacio, 2001), los cuales habían venido intervenido en el planeamiento urbanístico de Santoña durante la segunda mitad del siglo XIX, de acuerdo con el Real decreto de 18 de diciembre de 1842, en el que se establecía que el cuerpo de Ingenieros del Ejército constaría en toda España de 198 jefes y oficiales para el servicio de los 14 distritos militares y la plaza de Ceuta ${ }^{24}$.

Por otro lado, la asignación de funciones penitenciarias no era novedosa en Santoña, puesto que antes de la elección del Dueso para la construcción de la nueva colonia, existía ya un penal, contiguo al núcleo de población, en la zona de la dársena, cuyo edificio había desempeñado distintos usos hasta llegar a convertirse en establecimiento penitenciario (Palacio, 2001); como por otro lado era lo habitual en las cárceles del siglo XIX, muchas de ellas procedentes de antiguos conventos o palacios y edificios militares en desuso (Fraile, 1987a). El viejo penal de Santoña era una prisión aflictiva de aglomeración que aún se mantuvo en funcionamiento en las primeras décadas del siglo $\mathrm{XX}^{25}$ y que en los

22 «C'est à cette époque que les soldats donnèrent le nom de Gibraltar français à cet ouvrage de leurs mains. Nul ne doute que si les Anglais se fussent emparés de Santoña, ils n'eussent fait de cette place un véritable Gibraltar du nord de la Peninsule», en Victoires, conquêtes, désastres, revers et guerres civils des français. Tome trenteunième. Paris, Imprimerie de C.L.F. Panckoucke, 1831: 9.

23 Más adelante señala que «ningún acorazado puede franquear la barra de Santoña; tampoco pueden hacerlo la generalidad de los cruceros de $1^{\mathrm{a}}$, y sí solo parte de ellos y los de $2^{\mathrm{a}}$ y $3^{\mathrm{a}}$ clase, aprovechando horas determinadas de la marea» (Memorial de Ingenieros, $\mathrm{n}^{\circ} 2$, febrero 1893: 34).

24 A partir de la supresión de la Comandancia de Santoña, se pasó a formar parte de la jurisdicción de la Comandancia de Ingenieros de Bilbao, cuyo jefe en 1907 era el teniente coronel José Kith y Rodríguez.

25 En la Gaceta de Madrid de 1908 se publican las subastas públicas del suministro de víveres para los reclusos de la prisión de penas aflictivas de Santoña y para la colonia penitenciaria del Dueso (6/12/1908 y 21/11/1908), lo cual demuestra la coexistencia, en ese mismo año, de ambos establecimientos. Más tarde, a finales de 1919 (Gaceta de Madrid, de 3/12/1919), coincidiendo con una nueva reforma de las escalas, de las categorías y del número de los funcionarios adscritos a cada una de las prisiones españolas, se fija la distribución del personal tanto para la prisión de Santoña como para la colonia penitenciaria del Dueso, consideradas ambas prisiones generales. No obstante, el diario La Época de dicho año, 30/10/1919, indica que una comisión de senadores y diputados de la provincia de Santander había reiterado al ministro de Gracia y Justicia su solicitud para la desaparición del viejo penal de Santoña. Por aquel entonces el número de presos que todavía se hallaban en dicho penal era de unos quinientos. 
años previos a la construcción de la colonia penitenciaria del Dueso conoció un elevado hacinamiento de presos condenados a penas mayores ${ }^{26}$ (Collado, 2002).

Tales condiciones habían sido la causa de frecuentes evasiones y conatos de fuga, lo mismo que de abundantes enfermedades entre los reclusos ${ }^{27}$. Todavía en 1902, el viejo penal siguió incrementando su número de presos, ya que en este año se transfirieron todos los sentenciados a reclusión temporal del penal de Tarragona al de Santoña, siendo en total 295 los trasladados ${ }^{28}$. Pocos años antes, en 1898, se habían sacado a concurso obras de reforma y ampliación del destartalado penal santoñés, con un presupuesto de 186.643,98 $\operatorname{pesetas}^{29}$.

Esta situación de concentración de penados, sin distinción de delitos ni edades y abocados a una inactividad forzosa, había sido usual en otras prisiones españolas a lo largo del XIX (Fraile, 1987a). Desde hacía décadas, éste era uno de los principales argumentos a favor de la reforma de la arquitectura y de las condiciones de vida penitenciarias, propósitos que, sin embargo, habían sido postergados repetidas veces, debido sobre todo a las estrecheces presupuestarias del Estado.

Como dato puntual, entre finales de 1896 e inicios de 1897, José Millán Astray, funcionario de Prisiones y padre del futuro fundador de la Legión, fue destinado como director interino del antiguo penal de Santoña, al reintegrarse en el cuerpo de Prisiones, tras un período de excedencia, solicitada en $1892^{30}$. Su presencia en Santoña se mantendría tan sólo hasta junio de 1897, cuando fue nombrado director del penal de Burgos ${ }^{31}$.

26 El preámbulo del Real decreto de 11/8/1888 que establece una clasificación de los establecimientos penales españoles señala: «En los presidios de Alcalá de Henares, Santoña, Valladolid, Alhucemas, Chafarinas, Melilla y Peñón de la Gomera no cabe un penado más; están próximos á llenarse el presidio de San Miguel de los Reyes y la prisión celular de Madrid». En 1895, según datos de la Revista de las prisiones ( ${ }^{\circ}$ 8, 23/2/1895), la población del penal de Santoña era de unos 600 presos. En el mismo año, refiriéndose a dicha población reclusa, la misma revista ( $\left.{ }^{\circ} 19,15 / 5 / 1895\right)$ indicaría que «es sin duda la más insubordinada que en los Penales existe» y proseguía explicando que dicha situación «dimana de las frecuentes mudanzas de Jefes, del carácter interino que la mayor parte de ellos han tenido, y sobre todo, de la falta de trabajo y ocupación que allí tienen los reclusos». En septiembre de aquel año, la mencionada revista $\left(n^{\circ} 34\right)$ publica otro artículo sobre la penitenciaría de Santoña, firmado por Manuel de Cossío y G. Acebo, en el que se manifiesta que el establecimiento contenía unos 900 penados, siendo un «pudridero humano, pues no otro nombre merece aquel edificio capaz solo para 400 corrigendos, y no para la numerosa población penal que en él sufre condena». Uno de los principales problemas recogidos en el artículo era el abastecimiento de agua potable, aunque también se hace referencia a las pésimas condiciones de los dormitorios, concluyéndose que «así pasan la vida aquellos desgraciados, que, no por el mero hecho de ser criminales, dejan de ser hombres que merecen y tienen derecho á las atenciones y consideración de sus semejantes».

27 Como se explica en la Revista de las prisiones, $\mathrm{n}^{\circ} 45,15 / 12 / 1895$, en artículo firmado por Álvaro Navarro de Palencia, por aquel entonces director del establecimiento.

28 Revista de las prisiones, $\mathrm{n}^{\circ} 13,1 / 4 / 1902$.

29 Gaceta de Madrid, 27/1/1898.

30 Revista de las prisiones, $n^{\circ}$ 9, 10/1/1897. En noviembre de 1896, José Millán Astray padre llega a subjefe de la policía especial de Madrid, encargándose de la persecución de anarquistas, según recoge la Revista de las prisiones de 1/11/1896.

31 En la Guía oficial de España de 1888: 359, Millán Astray aparece como subdirector de la cárcel Modelo de Madrid, tras ser designado por la Junta de Prisiones. A dicha plaza también se presentó Rafael Salillas, no obstante, mediante una instancia, Millán logró que la candidatura de su oponente fuera desestimada (Revista de las prisiones, 8/3/1902: 151). 
Figura 4

VISTA DE SANTOÑA FINALES DEL S. XIX, PALACIO DUQUE DE MANZANEDO (A LA DERECHA), INSTITUTO MARQUÉS DE MANZANEDO (EN EL CENTRO), MONTEHANO Y MARISMAS (DIFUMINADOS AL FONDO)

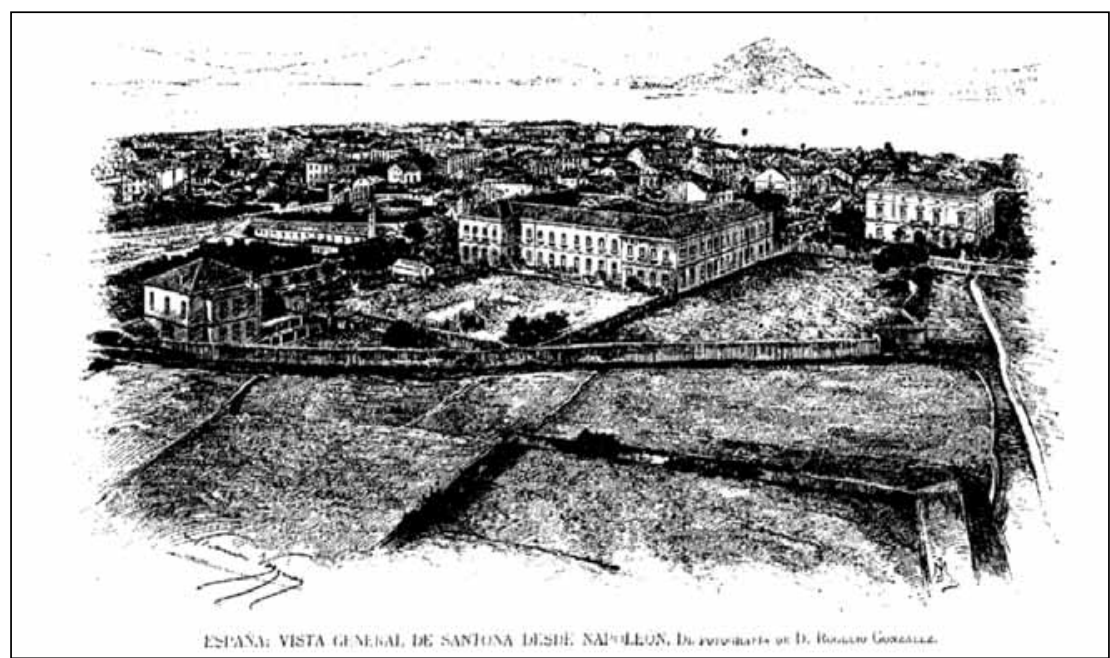

Fuente: La Ilustración (Barcelona), 23/2/1890, n 486, p. 116.

\section{III.2. El traslado de reos de los presidios africanos a la Península, el Dueso y la materialización de los objetivos de reforma penitenciaria}

En este contexto, el 7 de mayo de 1907, aparecía en la Gaceta de Madrid, nº 127: 515516, el Real decreto firmado por el Ministro de Gracia y Justicia, Juan Armada y Losada, marqués de Figueroa, para trasladar la población penal de los presidios del Norte de África a la Península y crear así la colonia penitenciaria del Dueso. Estos presidios africanos eran los de Ceuta y Melilla y otros tres menores, situados sobre promontorios o islotes rocosos: Chafarinas, Alhucemas y Peñón de Vélez de la Gomera. En ellos se cumplían penas de cadena perpetua y temporal, como recogía el art. 3 del Real decreto de 10 de mayo de 1902, por el que se dictaba una nueva clasificación para los establecimientos de prisiones españoles (Revista de las prisiones, de 16/3/1902). En la Conferencia internacional de Algeciras, celebrada entre mediados de enero e inicios de abril de 1907, uno de los compromisos adquiridos por España había sido el traslado a la Península de la población penal de dichos enclaves africanos, cuya ocupación representaba un importante contencioso territorial con Marruecos (El País, 26/2/1907 y El Siglo futuro, 27/2/1907). El propósito de acabar con los presidios africanos había sido formulado como acuerdo de Gobierno en 1904, enlazando con la larga aspiración de reforma del sistema penitenciario español a la que ya hemos hecho mención ${ }^{32}$ (Burillo, 2011).

32 «No se debe por más tiempo consentir que nuestro sistema penal se reduzca á una especie de régimen de prisión para tener encerrados á los hombres durante el período señalado por la ley», señala una Real orden de 10 de mayo de 1904, a la que se alude en el propio Real decreto de 1907, en su exposición de motivos. 
El término «presidio», en el caso de los africanos, tenía una gran carga histórica: hacía referencia a la función militar como fortaleza en territorio hostil y al confinamiento para el cumplimiento de penas. Conocedor de estos significados, el Consejo Penitenciario constituido también en $1904^{33}$, vinculó la propuesta de trasladar la población reclusa de los presidios de África a territorio peninsular con la necesidad de transformación y mejora de los establecimientos penitenciarios españoles.

Por lo demás, este traslado de presos no sólo tuvo como consecuencia directa la creación de la nueva prisión de Santoña, que se llevaría a cabo en los años sucesivos, sino también la preparación o transformación de otros establecimientos ya existentes en otros lugares de la Península y que hubieron de hacerse cargo, de manera precipitada, de la población penal desplazada. Es el caso del Castillo de Figueras ${ }^{34}$, de la prisión central de Ocaña ${ }^{35}$ y de la de San Miguel de los Reyes en Valencia ${ }^{36}$.

La elección del emplazamiento santoñés, ocupando lo que había sido la posición militar conocida como «Fuerte y plaza de armas del Dueso» ${ }^{37}$, en la falda noroeste del peñón de Santoña, dominando el Cantábrico y la playa de Berria, se justificaba por ser éste un lugar aislado, elevado sobre el nivel del mar, despejado y bien aireado, con una situación prominente por todos sus frentes. Ya hemos señalado que tales circunstancias motivaron su consideración como entorno adecuado para el trabajo al aire libre, lo que a su vez permitía poner en marcha todo un «ensayo de colonización penitenciaria, susceptible de grandes desenvolvimientos y mejoras» (Real decreto de 7 de mayo de 1907). En la misma dirección se expresa el autor del artículo titulado «La nueva penitenciaría del Dueso» publicado en la Revista penitenciaria, tomo IV, de 1907, señalando que «El sitio no puede ser más atractivo,

33 Real decreto creando, en sustitución de la Junta general de Prisiones, un Consejo Penitenciario como cuerpo consultivo en asuntos de administración, régimen y reforma penitenciaria (Gaceta de Madrid de 24/04/1904: 307-308). Como ya hemos indicado, su órgano oficial fue la Revista penitenciaria, publicada en Madrid en la imprenta de Eduardo Arias, en ella escribe Salillas, Secretario general del Consejo. Dicho Consejo Penitenciario se suprime por Real decreto de 22/3/1915, (Gaceta de Madrid de 24 de marzo: 860).

34 El Real decreto de 18 de octubre de 1906 (Gaceta de Madrid,21/10/1906) establecía su transformación en penitenciaría. Con respecto a dicho castillo, Lorenzo de la Tejera dice lo siguiente: «Puede parecer á primera vista, que al utilizar parte del castillo de San Fernando se cae en el inconveniente mismo que trajo consigo el aprovechamiento de los conventos; pero no es así, pues el sistema de construcción de esa fortaleza permite establecer una penitenciaría en bastantes buenas condiciones aprovechando la parte destinada a este fin, sin que el conjunto de ella pierda nada» (en Memorial de Ingenieros del Ejército, octubre de 1907: 331). El proyecto de Figueras se encarga al ingeniero militar Arturo Vallhonrat, quien lo realiza entre 1907 y 1909. Las obras se efectuaron con penados del presido de Tarragona.

35 Cuyo solar, antes de convertirse en cárcel, albergó en el XIX, las funciones de cuartel de caballería. En 1907, se llevaron a cabo obras de reforma, con un presupuesto inicial de $122.816,45$ pesetas, como consta en el Real decreto de 29 de abril de aquel año (Gaceta de Madrid, 1/5/1907). Dichas obras continuaron en 1910, cuando se construyó una cocina en pabellón aislado, se instalaron baños, se mejoró la distribución de agua, se revocaron fachadas y se arreglaron tejados (Real decreto, Gaceta de Madrid el 26 de febrero de 1910). El Real decreto de 30 de octubre de 1914, lo transforma en reformatorio de adultos (Gaceta de Madrid, 1/11/1914), siendo el primero en España con esta denominación.

36 Antiguo monasterio desamortizado y propiedad del Estado desde 1835. Fue utilizado como asilo de indigentes, cárcel de mujeres y presidio. El 12 de julio de 1907, se publica en la Gaceta de Madrid una Real orden aprobando las obras, a ejecutar por los propios penados del establecimiento (p. 133-134).

37 Durante la ocupación francesa, a comienzos del XIX, se construyó en esta misma zona del barrio del Dueso el llamado Fuerte imperial de Napoleón, para controlar los accesos a Santoña a través del istmo de Berria (Palacio, 2004). 
ni mejores las condiciones de aislamiento y seguridad naturales. Toda una parte de la penitenciaría estará asegurada por las mismas escotaduras del terreno, otra por el mar y otra por las marismas, que constituirán desenvolvimientos que se han de conseguir con el trabajo de los penados».

El sitio, de unas 33 hectáreas, reunía otras condiciones fundamentales para el control y la vigilancia, reduciendo al máximo las posibilidades de evasión: el único punto de salida por vía terrestre era, como hemos dicho, el istmo de Berria que conducía a la carretera de Santoña a Cicero. Por lo demás, la zona quedaba enclavada entre la playa de Berria, el área de marismas y el peñón de Santoña, este último con una elevación máxima de 378 metros y abundante arbolado de encinas.

El estudio de la localización más apropiada para la construcción del nuevo penal fue uno de los principales motivos para la creación de la Comisión regia, por Real orden de 15 de febrero. Esta Comisión estuvo integrada por el Director general de Prisiones, Ángel García Rendueles, el entonces director de la cárcel Celular de Madrid, Rafael Salillas y el ingeniero del ejército Lorenzo de la Tejera y Magnín. En marzo de 1907 la Comisión se desplazó por primera vez a Santoña (Revista penitenciaria de este año, tomo IV), con el objetivo de «estudiar sobre el terreno la forma en que en la fortaleza del Dueso podría establecerse una colonia penitenciaria, montada á la moderna, de modo que los penados puedan trabajar al aire libre, con utilidad y provecho para el Estado y la villa de Santoña» (La Época, 8/3/1907).

Por tanto, dicha Comisión, fundamentalmente en la figura del ingeniero Lorenzo de la Tejera, fue responsable de los proyectos de instalación, de la confección de los planos y del programa para la construcción de la penitenciaría ${ }^{38}$. El 7 de junio de 1907, una Real orden concede a dicho militar todas las atribuciones necesarias como Comisario regio de la colonia, cargo en el que se le confirma por otra Real Orden del 30 de diciembre de 1910.

La atribución de responsabilidades a un representante del ejército, el entonces comandante de ingenieros Lorenzo de la Tejera, venía acreditada por el carácter defensivo del emplazamiento, inicialmente propiedad del Ministerio de la Guerra, y se regía por el artículo $1^{\circ} \mathrm{del}$ Reglamento para la ejecución de las obras y servicios técnicos que tiene a su cargo el Cuerpo de ingenieros del ejército ${ }^{39}$, aprobado por Real orden de 4 de octubre de 1906. Tras las primeras reuniones de la Comisión, dicho responsable diría lo siguiente: «Pocas sesiones fueron necesarias para que me diera cuenta de que el asunto tenía bastante más importancia de lo que á primera vista pudiera parecer, pues se trataba á la vez de establecer una penitenciaría con arreglo á las ideas que, en las naciones de más avanzada cultura, dominan hoy respecto al particular, dando de este modo un paso decisivo en la reforma de nuestro régimen penitenciario, que por cierto se encuentra muy necesitado de ella» (Memorial de Ingenieros del Ejército, no ${ }^{\circ}$ 10, octubre de 1907: 329).

De la Tejera fue un indudable defensor de la fórmula de trabajo al aire libre, por considerarla beneficiosa, no sólo desde el punto de vista moral e higiénico, sino también económico para el Estado. Al mismo tiempo, era partidario de las ideas de reforma del sistema peniten-

38 Lorenzo de la Tejera: Algunas ideas sobre arquitectura é ingeniería penitenciarias: la colonia penitenciaria del Dueso. Memoria presentada en el primer congreso científico celebrado por la Asociación Española para el Progreso de las Ciencias, Zaragoza, octubre 1908, 16 p.

39 Madrid: Imprenta del Memorial de Ingenieros del Ejército, 1906, 207 p. 
ciario y buen conocedor de los estudios de Salillas y de los trabajos de Concepción Arenal, como él mismo declara en sus escritos ${ }^{40}$. Para el proyecto del Dueso, Tejera había estudiado con profundidad diversos documentos sobre arquitectura penitenciaria, en especial los relativos a cárceles rusas, proporcionados por Salillas ${ }^{41}$ y había visitado varias de las cárceles y presidios existentes entonces en España.

Elegido el lugar y establecida la gestión facultativa de las obras que debían llevarse a cabo, la ejecución material del centro penitenciario de nueva planta se apoyó, desde el primer momento y como ya hemos señalado, en el empleo directo de los penados, instalados provisionalmente para tal efecto en el cuartel del Dueso y en otras dependencias militares anejas, cuya adecuación al desempeño de tales fines corrió a cargo del maestro de obras militares Manuel Arroyo Fernández.

\section{INICIO DE LOS TRABAJOS DE CONSTRUCCIÓN Y PRIMEROS OBSTÁCULOS PARA LLE- VAR A CABO UN COLOSAL PROYECTO}

Recién aprobado el Real decreto de 1907, el comienzo de la construcción del grandioso proyecto arquitectónico del Dueso fue relativamente rápido. Sin embargo, la celeridad inicial se vio pronto ralentizada al irse planteando los primeros problemas, tanto económicos como materiales.

\section{IV.1. Las dimensiones previstas para la colonia y el acondicionamiento de terrenos}

En un principio, conforme a los planes de Lorenzo de la Tejera, se preveía que el establecimiento llegara a alcanzar una capacidad total de mil plazas al final de las obras, distribuidas en tres períodos de reclusión según la clasificación individual de los presos, lo que representaba un sistema similar al denominado progresivo o de Crofton, implantado en Irlanda en 1883 y en todo caso, conforme al Real decreto de 3 de junio de 1901²: el primero de aislamiento celular absoluto, el segundo de trabajo industrial y agrícola en comunidad durante el día y el tercer período expansivo o de libertad intermedia, siempre dentro del régimen de trabajo en los talleres y campos de la colonia. En todos los casos, el aislamiento individual de los reclusos se mantendría durante la noche.

Para ello, el decreto de creación del Dueso en 1907 establecía la construcción de pabellones aislados: un edifico celular separado, con unas 200 celdas, otros dos edificios con 300 celdas cada uno, utilizados tan sólo para pernoctar, contando como anexos con diferentes locales para el trabajo y el estudio, y finalmente otros edificios para el tercer grado, con

40 Memorial de Ingenieros del Ejército, $\mathrm{n}^{\circ}$ 10, octubre, 1907: 333.

41 Quien en 1890 había asistido al Congreso Internacional Penitenciario de San Petersburgo, visitando los establecimientos de esta ciudad y de Moscú.

42 Gaceta de Madrid de 7/6/1901. En dicho decreto se reconoce que para la aplicación del sistema progresivo irlandés o de Crofton en España «han de reunir los edificios condiciones de que carecen la mayor parte de los actuales», de manera que «no es, pues, posible implantar en todos los Establecimientos el sistema que se indica, desde luego, por falta de celdas para el período de preparación, y es necesario recurrir al que más se le asemeje. Es éste el de clasificación, que, apartando á los penados en grupos por razón de los delitos y condenas, y reuniendo en cada agrupación á los que se hallen en más parecidas condiciones, se aproxime la disciplina, en cuanto sea posible, al tratamiento individual que persigue la ciencia penitenciaria». 
capacidad para 200 penados, perdiendo en este caso «los caracteres más determinantes de la prisión» y aproximándose «al tipo de la casa» y «al de la familia». Además, se fijaba la creación de dependencias y servicios administrativos, locales de acuartelamiento y suministros y viviendas para los empleados (Figura 5).

De acuerdo con el mencionado decreto de 1901, esta clasificación individual de los reclusos suponía «un tratamiento en que sucesiva ó simultáneamente actúe sobre su espíritu la acción del aislamiento, del trabajo, de la enseñanza primaria, religiosa é industrial, el rigor saludable de prudenciales castigos y el estímulo bienhechor de merecidas recompensas, á fin de que vayan poco á poco despertando en su conciencia el arrepentimiento de la culpa, y en su corazón el propósito de tornar á la honradez, preparándoles para la vida libre á medida que se acerque el fin de su condena».

Un régimen semejante ya había sido implantado una década antes en el presidio de Ceuta, desde donde, a medida que se inicia la construcción de la nueva prisión de Santoña, empiezan a desplazarse los primeros reos. Este sistema para la organización de la población penal de Ceuta se debe al Real decreto de 23 de diciembre de 1889, según el cual se establecían cuatro grados: celular o de aislamiento, instructivo, intermedio y de circulación libre dentro del ámbito de la colonia ${ }^{43}$.

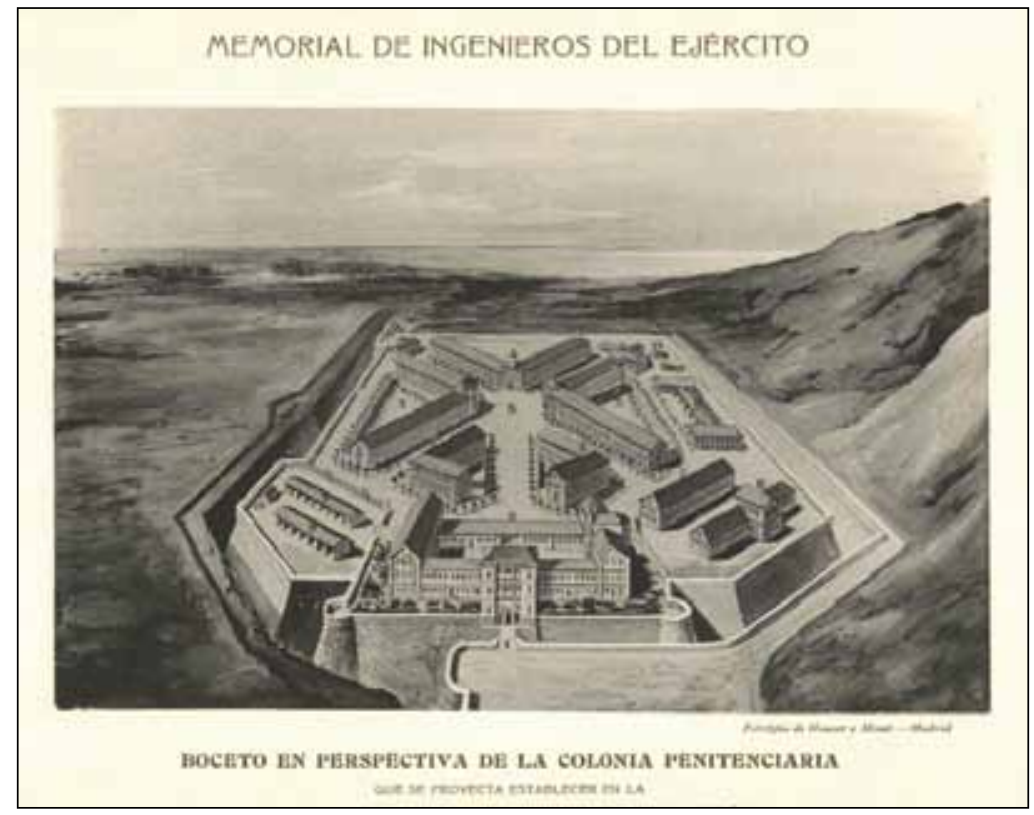

Fuente: Memorial de Ingenieros del Ejército, octubre 1907, año LXII, n ${ }^{\circ} \mathrm{X}$.

43 Gaceta de Madrid de 25/1/1889, donde se dice: «La celda y el taller son los dos medios eficaces de regeneración del culpable». 
Para los defensores de estos procedimientos de reforma penitenciaria, siguiendo el modelo instaurado en otros países, el objetivo era dignificar al preso mediante el trabajo, combinando para ello la reclusión con la enseñanza, el trabajo en el taller y la actividad agrícola o industrial, asociando así, en definitiva, pena con redención ${ }^{44}$.

De acuerdo con el intento de aplicar estos planteamientos teóricos, en los primeros años de funcionamiento provisional del Dueso, se acometieron intensos trabajos de desmonte y explanación, necesarios para la posterior instalación de los distintos edificios proyectados. De estos edificios, los primeros en construirse fueron uno de los diseñados para el cumplimiento del segundo período de reclusión y un grupo de talleres, en el ángulo suroeste (Figura 6). En realidad, éstas serían las únicas previsiones constructivas del proyecto inicial que se llevaron a cabo.

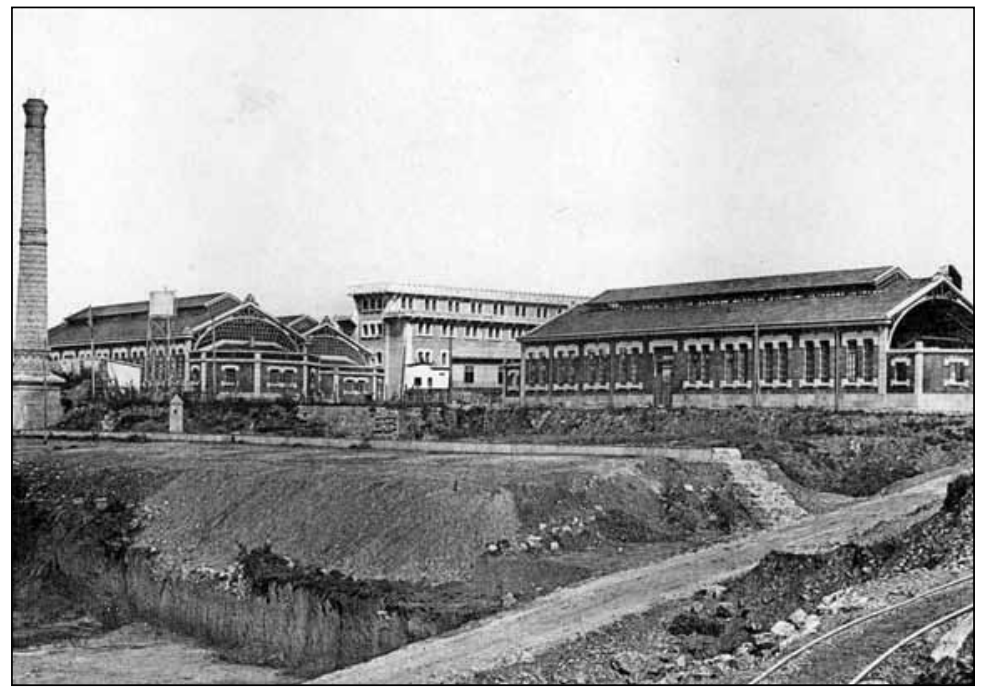

Fuente: Tarjeta postal, colección particular.

Con las tierras removidas se construyeron diques para la desecación de las marismas y la consiguiente ampliación de terrenos, labor considerada sumamente útil, al ser el empiece del posterior aprovechamiento agrícola, por parte de los presos, de los terrenos obtenidos ${ }^{45}$. Además, tales actuaciones de creación de suelo a partir del rellenos de las marismas se anticipan a la denominada Ley Cambó, de 24 de julio de 1918, favorable a la desecación en toda España de este tipo de territorios de humedales, considerados insalubres e improductivos.

44 Exposición previa de motivos para el Real decreto de 23/12/1889.

45 La intervención de delincuentes en el saneamiento de terrenos pantanosos e incultos ya había sido propuesta, para el caso de Italia, por Enrico Ferri en su obra de 1884, de la que hemos hecho mención anteriormente. 
En estos primeros años, también se pusieron en explotación varias canteras (Figura 7) con vistas a la obtención de piedra que se usaría para la construcción del cierre del penal a lo largo de todo su perímetro. Igualmente, en 1909, se instalaron dentro del recinto dos depósitos de agua para abastecer a la colonia. Todos estos trabajos, como ya hemos dicho, fueron efectuados por los propios penados, según los principios que habían servido de base para la creación de la colonia.

Un elemento al que se dio una gran importancia fue el alumbrado nocturno de todo el entorno en construcción, como dispositivo de vigilancia y para evitar accidentes intencionados o fortuitos, lo mismo que posibles evasiones. De esta manera se establecieron una batería de acumuladores, una central transformadora de corriente y varios circuitos independientes, a fin de minimizar las interrupciones de suministro electrónico (Figura 8). Sin embargo, a pesar de estas medidas de control, durante el período de realización de las obras de la colonia se llegaron a producir algunas fugas o intentos de fuga, como consta en varias publicaciones periódicas de estos años ${ }^{46}$.

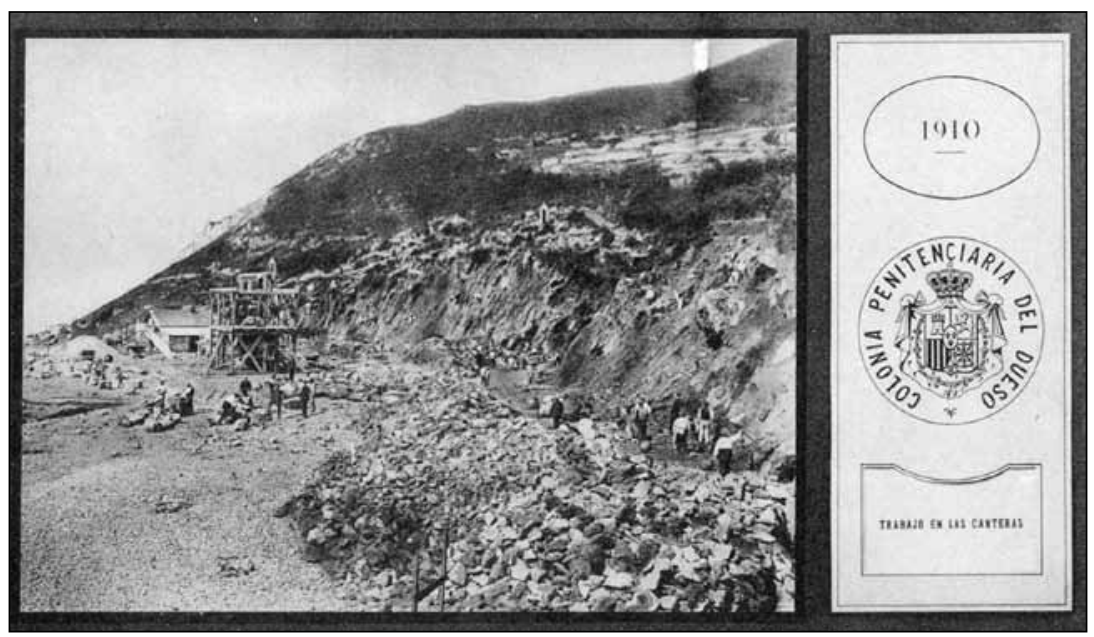

Fuente: Tarjeta postal, colección particular.

46 Así, en La Correspondencia de España, 11/6/1909, aparece un anuncio sobre la fuga de un recluso: «Del Penal del Dueso, de Santoña, se fugó anoche el recluso Andrés Avelino Rodríguez Torres, natural de Ciaño de Langreo (Oviedo), de veintidós años, llevando el traje de rayadillo del Penal. Se ignora la dirección que habrá tomado, creyéndose que esté oculto en los montes próximos. La benemérita ha salido en persecución del fugitivo para reconocer los lugares en donde haya podido refugiarse». En ese mismo año, aparece otro anuncio en El Imparcial de 24 de junio: «Esta tarde á las cuatro, cuando habíanse suspendido los trabajos en el penal de Dueso á causa de la lluvia, pasóse lista á los penados y se notó la ausencia de Eugenio de Blas y Francisco Saenz. Ésto produjo cierta inquietud entre los vigilantes del penal, por cuanto Eugenio, forajido de pésima nota, consiguió evadirse hace años de la prisión y se temió que ahora en compañía de otro recluso hubiera repetido la audacia. Registradas las dependencias del penal hallóse á los dos individuos citados ocultos en la alcantarilla de los talleres, aguardando, sin duda, la noche para saltar al campo». 


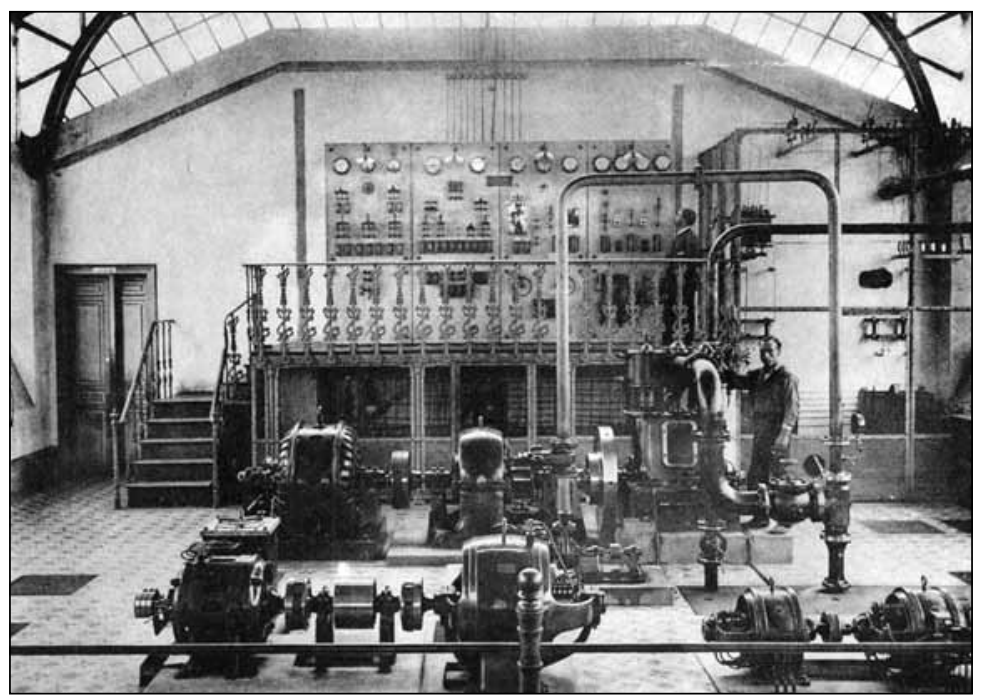

Fuente: Tarjeta postal, colección particular.

En relación con las condiciones de seguridad y con esta proximidad espacial entre penados y habitantes de las localidades cercanas, ya en los años anteriores, la instalación de presos procedentes de África en territorio peninsular había originado posturas en contra y protestas por parte de las poblaciones afectadas, no sólo en Santoña, sino también en otros lugares de Cataluña, especialmente en la población de Figueras y comarca del Ampurdán, o en Galicia, donde en la Isla de Sálvora, en la ría de Arosa, se proyectaba la construcción de una penitenciaría modelo y la desecación y cultivo de extensas marismas, según recoge $L a$ Lectura dominical en artículo publicado el 1/9/1906. «Cuando se conoce la situación de Santoña, que se halla geográficamente en cierto aislamiento, se comprende que se haya podido difundir una creencia muy generalizada en aquella localidad: la de que el presidio de Ceuta iba á ser allí instalado tal y como lo está en nuestra ciudad africana, transformándose, por lo tanto, la ciudad de Santoña en un nuevo Ceuta, es decir, en una ciudad penitenciaria (sic) donde los penados transitarían libremente en el cuarto período de su pena ${ }^{47}$. En el discurso y en el imaginario colectivo se empezaban a gestar una serie de elementos que iban a ir configurando la imagen de Santoña vinculada a su nuevo penal.

\section{IV.2. Surgen y crecen las dificultades}

Frente a todas las previsiones, los contratiempos para el desarrollo material del proyecto se fueron incrementando, ya que a pesar de contar con esta mano de obra forzosa de penados

47 Revista penitenciaria, tomo IV, 1907: 186. En el periódico El Día, de 3/5/1907, se publicó un artículo en el mismo sentido, relatando las circunstancias que concurrían en la plaza militar y colonia penitenciaria de Ceuta. Opiniones también en contra del traslado a la Península de los deportados se expresan en La Correspondencia de España de 5/2/1905. 
que trabajaban, de sol a sol, a jornal o a destajo en las tareas a las que habían sido destina$\operatorname{dos}^{48}$, los costes de explanación de los terrenos, de cimentación de los primeros edificios y de desecación de las marismas resultaron más elevados de lo previsto, lo mismo que la expropiación de algunas parcelas pertenecientes a particulares. Además, la amplitud de muro de cierre de la colonia, con sus respectivos cuerpos de guardia, también representó de por sí unos gastos considerables.

De esta manera, las obras se fueron demorando y prolongando en el tiempo. Cinco años después de presentado el proyecto, en 1912, los trabajos del Dueso seguían en ejecución, mientras que el moderno e impresionante modelo arquitectónico elegido para albergar a presos sometidos, en su mayor parte, a las máximas condenas, así como la cuantía creciente de los trabajos, daban lugar a importantes discusiones de ámbito nacional.

Es ésta la razón por la que en dicho año se resuelve incrementar la capacidad futura del penal en construcción, pasando de las mil a las mil quinientas plazas, a fin de rentabilizar los trabajos y poder además cerrar algunos otros penales como los de Tarragona, Burgos y Granada. De haberse cumplido realmente estas expectativas para el Dueso, tal volumen de presos hubiera llegado a representar, aproximadamente, el 20,5\% de la población de Santoña en $1920^{49}$.

Igualmente, en dicho año de 1912 se toma, mediante decreto, la decisión de que, a partir de entonces, los presos que cumplieran condena en el Dueso debían ser los sentenciados a penas que no se consideraran «eliminatorias» desde el punto de vista de su posterior integración social, dado que el trabajo que iban a realizar dentro de la colonia se pretendía que tuviera un carácter educativo y de regeneración, «con objeto de que la sociedad pueda apreciar los buenos resultados del sistema y beneficiarse pronto de ellos» ${ }^{50}$.

De la misma forma, en lo que hace referencia al control económico y a la gestión de las obras aún por acometer, en el mencionado decreto de 1912 se indica que «tanto el Director de la Colonia, como el Administrador y el Ayudante de servicio, recorrerán diariamente, el mayor número de veces posible, los diferentes tajos, para cerciorarse de que los vigilantes permanecen en sus puestos y prestan al servicio la debida atención, haciendo que los reclusos desplieguen la mayor actividad posible en el trabajo» (Gaceta de Madrid de 28/01/1912: $291)^{51}$. El objetivo implícito era dar un mayor impulso a unos trabajos de construcción que se habían ido demorando más de lo pronosticado.

48 No se les permitía llevar a cabo trabajos por su cuenta, ni que pudieran serles útiles o productivos. De otra parte, los penados reacios al trabajo encomendado permanecían recluidos o formaban parte de brigadas especiales para trabajar, todo o buena parte del día, separados del resto y sin pago alguno de jornal (Gaceta de Madrid de 28/01/1912: 292).

49 Por otras razones, a volúmenes bastantes superiores se llegaría tras la Guerra Civil, cuando se establecieron cuatro campos de detención: el propio penal del Dueso, el cuartel de infantería, el fuerte de San Cristóbal y el instituto Manzanedo (Collado, 2002).

50 Real decreto disponiendo que en la posición militar del Dueso (Santoña) se construya un grupo penitenciario, que se compondrá de la colonia industrial y agrícola creada por Real decreto de 6 de mayo de 1907 (Gaceta de Madrid de 28/01/1912: 290).

51 Quien respalda con su firma todos estos proyectos es José Canalejas, entonces ministro de Gracia y Justicia, unos meses antes de morir en atentado. 


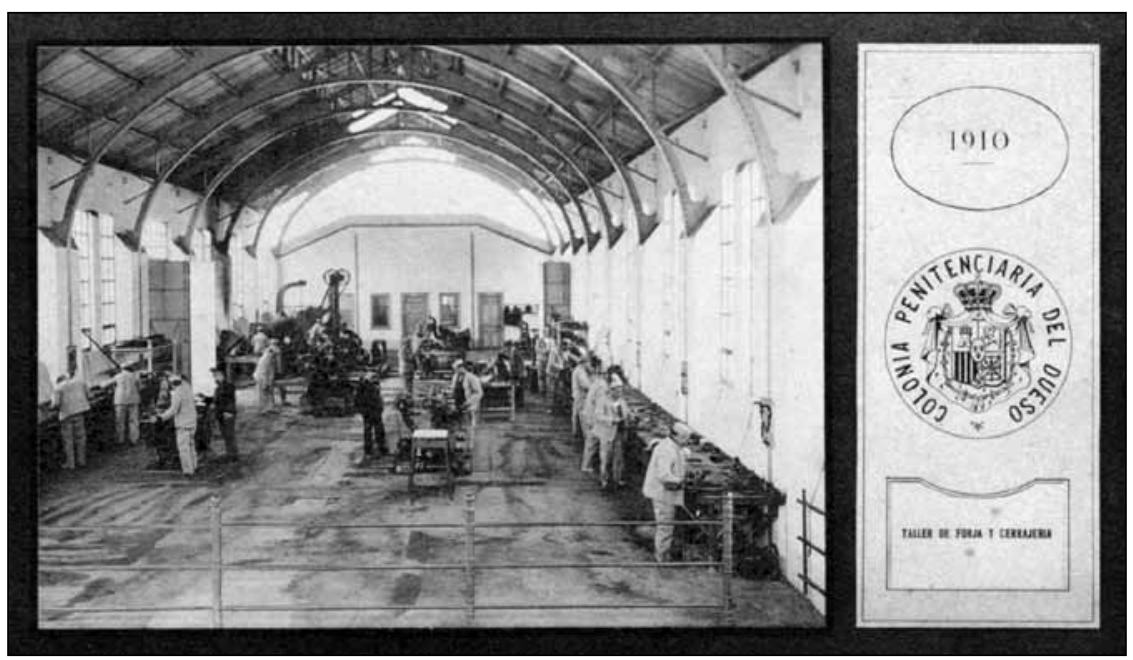

Fuente: Tarjeta postal, colección particular.

En esta línea, desde los primeros años, los penados del Dueso, además de dedicarse a la construcción del establecimiento, trabajaban en los talleres de forja, cerrajería y carpintería que se habían ido estableciendo en relación con las propias obras de edificación (Figura 9). Conjuntamente, ya antes de 1912, se habían empezado a impartir, de manera incipiente, algunas enseñanzas en materia agrícola a cargo de un ingeniero agrónomo. Se pensaba así llegar a obtener productos que pudieran consumirse dentro de la colonia, pero sobre todo la principal intención era conseguir la desecación de más de seiscientas hectáreas de marisma que habrían de aprovecharse para cultivos: «La índole misma de este trabajo, le hace muy á propósito para ser realizado por penados, como lo demuestra el empleo que de los mismos se hace en distintas naciones, para desecar y poner en cultivo terrenos pantanosos» (Gaceta de Madrid, 28/1/1912: 290).

\section{CONCLUSIONES: UN PROYECTO REFORMISTA INCONCLUSO}

Pese a todas estas nuevas disposiciones legislativas y reglamentarias, establecidas en 1912 con la intención de dar un empuje concluyente al que había sido planteado como un substancial propósito arquitectónico y organizativo de reforma penitenciaria y de colonización interior, el proyecto de Lorenzo de la Tejera, autor material y de Rafael Salillas, autor ideológico, siguió aplazando su realización definitiva.

A finales de junio de 1915, con el penal todavía en construcción, de la Tejera cesa como director y administrador de las obras del Dueso. En los meses siguientes, estando al frente del Ministerio del ramo Manuel Burgos y Mazo, se suprime la Comisión regia creada en 1907. Sus atribuciones son transferidas a la recién creada Comisión asesora de la reforma de las Prisiones, también llamada Comisión Asesora de la reforma penitenciaria y Ordenación 
del trabajo. En septiembre de 1915, los trabajos del Dueso se suspenden hasta el establecimiento de un nuevo plan de obras, si bien otro decreto de noviembre de ese mismo año dispone su reanudación inmediata.

En los años siguientes, cuando ya había sido modificado notablemente el trazado inaugural de Lorenzo de la Tejera, la prensa sigue recogiendo las dificultades económicas del conjunto de las obras aún previstas en la colonia penitenciaria: «lo que falta por hacer en dicha colonia supone unos seis u ocho millones de pesetas más, sin contar los seis gastados y los ocho que se solicitan para la anualidad de 1917» (en el diario conservador maurista $\mathrm{La}$ Acción, 4/12/1916).

Más tarde, en 1924, instalado ya un nuevo régimen político, el entonces Inspector general de Prisiones que no era otro que Fernando Cadalso, en un informe titulado La actuación del Directorio militar en el ramo de Prisiones, hace una ostensible crítica del modelo seguido en el grupo penitenciario del Dueso, desde su creación hasta septiembre de 1923 y afirma: «A partir del desacierto del Dueso se han sucedido varios criterios lesivos a los intereses públicos».

Una opinión tan negativa sobre la que, casi veinte años antes, se había diseñado como colonia penitenciaria modelo y ejemplo a seguir en materia de trasformación de la arquitectura penitenciaria en España debe interpretarse teniendo en cuenta que Cadalso, como ya hemos dicho, fue nombrado Ministro de Gracia y Justicia a finales de 1923, es decir al inicio de la dictadura primorriverista y que por lo tanto, estaba interesado en resaltar favorablemente la actuación del Directorio en el tema penitenciario, en comparación con la situación anterior, dando a entender que hasta entonces todo estaba por hacer ${ }^{52}$. Por lo demás, Fernando Cadalso mantuvo también constatadas desavenencias ideológicas y corporativas con Rafael Salillas, quien además ya no podía defenderse ni reivindicar sus ideales reformistas, puesto que acababa de fallecer en mayo de 1923.

El desacierto expresado por Cadalso no fue el proyecto de colonia penitenciaria en sí, adelantado y moderno, además de ampliamente estudiado y documentado por su principal artífice material, Lorenzo de la Tejera, conforme a los planteamientos de los penalistas más avanzados de la época y por tanto en la línea de la necesaria reforma del sistema penitenciario español. Los verdaderos obstáculos fueron la mudanza de criterios, la desorganización, los avatares políticos y legislativos sufridos y con ellos, la variedad de Directores generales y los conflictos internos dentro del cuerpo de Prisiones; sin olvidar los frenos más importantes: las dificultades encontradas en la financiación y en la gestión económica que acarrearon el cese de la Comisión regia.

En definitiva, todo el recorrido que hemos ido analizando pone en evidencia la inexistencia de una voluntad política capaz de conformar y llevar a la práctica un plan global de reforma para el conjunto de construcciones penitenciarias españolas, que todavía en la década de los años 20' del siglo pasado, seguían siendo en su gran mayoría viejos establecimientos ruinosos: ex conventos como en los casos de Burgos, Granada o Puerto de Santa María o antiguos castillos y fortalezas militares como los de Figueras y Chinchilla.

En este marco, desde el comienzo de su construcción, la colonia del Dueso había experimentado una continua renovación de los responsables de obras, a medida que se fueron

52 En El Imparcial de 27/5/1925 se defendían estos planteamientos de Cadalso y se hacía alusión al citado informe. 
introduciendo rectificaciones, criterios y planes nuevos y distintos a los precedentes; con lo cual, el resultado arquitectónico fue abandonando la mayor parte del trazado primigenio que jamás llegaría a desarrollarse en su integridad.

No obstante, la concepción esencial de la colonia penal como lugar de trabajo se mantuvo. Además, las ocupaciones diarias de los penados en los talleres industriales (de alpargatería, herrería, carpintería, cestería y zapatería) o en actividades agrícolas al aire libre (destacando el cuidado de reses vacunas) se fueron convirtiendo en representativas de la vida penitenciaria en el Dueso. Todo ello efectuado en el interior de la propia colonia, espacio de encierro y de esfuerzo activo, replegado sobre sí mismo, persistentemente controlado y vigilado, donde toda pérdida de tiempo se evita, el silencio se impone como disciplina y hasta el acceso a la ración diaria de alimentos se dosificaba, en aras de un mayor rendimiento productivo.

No sin una fingida ingenuidad, en el suelto titulado «Una mañana en el Dueso» del diario madrileño La Voz (19/10/1927), el articulista señala: «He presenciado el trabajo de los reclusos en las grandes naves de los talleres, que no tienen ni el menor asomo de arquitectura presidial, sino industrial. Son locales exentos de todo concepto de lobreguez; locales amplios, llenos de aire, de luz y, hoy, de sol. En uno de estos pabellones trabajan más de ciento treinta hombres: son los alpargateros, que inclinados sobre su banco, no tiene vista ni oído para nada que no sea su labor. El sistema de destajo imprime una actividad extraordinaria a la tarea. No se oye una voz, por queda que sea; no se oye más ruido que el que produce el golpeteo de la suela sobre el tablero. [...]. Los carpinteros-mueblistas, en su pabellón, trabajando igualmente, sin más preocupación aparente que la perfección de su obra. [...]. Recorro las demás secciones de trabajo, la de zapatería, la de metalurgia y la de almadreñas [...]. En otros locales reducidos hay talleres de juguetería y marquetería. [...]. Visito el economato, donde los colonos se surten de comida, de tabaco, de cuanto precisan para su vida de limitación. El economato tiene una cocina independiente de la del penal, que vende sus condimentos por raciones: cocido, carne, pescado, verduras. [...] Como los presos trabajan, pueden permitirse aumentar el rancho con estos «extras» del economato, o comer de restaurante».

Así, si por falta de fondos económicos, de organización y de verdadero interés político, los iniciales proyectos arquitectónicos de Lorenzo de la Tejera nunca llegaron a completarse, sin embargo, sí se consiguió establecer un estrecha relación entre la celda y el taller, entre reclusión y trabajo, entre control del penado y rendimiento material, como experimento de regeneración social, pero también de dominación de individuos a pequeña escala. La pretensión era lograr un tipo de recluso disciplinado que, además de exculpar su pena, se viera forzado a aprender un oficio y a asumir las normas del vivir ordenado y honrado ${ }^{53}$. El instrumento para conseguir estos objetivos, entre filantrópicos y represores, había de ser el propio espacio penitenciario, con su propio simbolismo arquitectónico, concebido y diseñado como herramienta de imposición ideológica y de gestión productiva de la fuerza de trabajo. En este sentido, pese a las complicaciones iniciales, el penal del Dueso resultó un auténtico éxito.

53 No olvidemos que un buen número de los presos que en los años 20' y primera mitad de los 30' se encontraban cumpliendo condena en el Dueso eran de ideología anarquista: uno de los más conocidos fue Juan Bautista Acher, «Shum» ó «el Poeta», dibujante y artista catalán, condenado a muerte en 1922, al ser acusado de actos de terrorismo; su pena sería luego conmutada a cadena perpetua. Junto con él, otros anarquistas recluidos en el Dueso en estos años 20' fueron José Donday, Luis Nicolau Fort, José Aracil, Leopoldo Martínez, Rafael Torres Escartín, Rafael Sancho Alegre, Santiago Alonso, Inocencio Domingo Lafuente, Celestino Cordero, Enrique Guiot, Nicolás López y Manuel Villalonga (La Revista Blanca, Madrid, 1900-1936). 


\section{REFERENCIAS}

ANSOLA FERNÁNDEZ, A (2000): «Surgimiento y consolidación de la Santoña pescadora, conservera y salazonera» en Santoña: de los escabeches a los salazones. La transformación de una villa litoral de Cantabria (Gómez Pellón, E., edt.). Santander, Universidad de Cantabria, 25-39.

BENEYTO FALAGÁN, N. (2013): «La colonia Santa Eulalia como utopía del territorio. Procesos de colonización interior en España a finales del siglo XIX», en GeoGraphos, Revista digital para estudiantes de geografía y ciencias sociales, vol. 4, nº 46, 323-354.

BURILLO ALBACETE, F.J. (2011): La cuestión penitenciaria. Del Sexenio a la Restauración (1868-1913). Zaragoza, Prensas de la Universidad de Zaragoza.

CAPEL, H. (coord.) (1990): Los espacios acotados. Geografía y dominación social. Barcelona, Promociones y Publicaciones Universitarias.

COLLADO QUEMADA, R. (2002): «Santoña y la colonia penitenciaria del El Dueso», en Monte Buciero, $\mathrm{n}^{\circ} 8,91-126$.

CHEJOV, A.P. (2005): La isla de Sajalín. Granada, Alba Clásica Mayor (edición original: 1895).

DELGADO CENDAGORTAGALARZA, A (1995): El penal del Dueso: historia de un nacimiento protestado, 1906-1915. Santoña, Coordinadora para la Recuperación de la Reserva de Santoña.

FRAILE, P. (1987a): Un espacio para castigar. La cárcel y la ciencia penitenciaria en España (siglos XVIII-XIX). Barcelona, Ediciones del Serbal.

FRAILE, P. (1987b): «La geografía del castigo. La distribución territorial de los presidios en la España del siglo XIX», en Estudios Geográficos, vol. 48, nº 186, 5-30.

FRAILE, P. (1997): «La cárcel y la ciudad: Montréal y Barcelona» en Desarrollo urbano comparado/Dévéloppement Urbain comparé, Barcelona-Montréal (Capel. H. y Linteau P.-A., coords.). Barcelona, Publicacions Universitat de Barcelona, 337-353.

FRAILE, P. (2007): «La percepción de seguridad: entre el delito, el conflicto y la organización del espacio» en Scripta Nova: Revista electrónica de geografía y ciencias sociales, vol. XI, no 245 (62). Disponible en http://www.ub.edu/geocrit/sn/sn-24562.htm

FRAILE, P. (2008) «Represión y conflicto en una sociedad globalizada» en Scripta Nova: Revista electrónica de geografía y ciencias sociales, vol. XII, $\mathrm{n}^{\circ} 270$ (1). Disponible en http://www.ub.edu/geocrit/sn/sn-270/sn-270-11.htm

FRAILE, P. y BONASTRA, Q. (2011): «Espacios, delincuencia y seguridad: hacia un diseño de un modelo de análisis territorial» en Boletín de la Asociación de Geógrafos Españoles, $\mathrm{n}^{\circ}$ 57, 123-146. Disponible en http://www.boletinage.com/57/06-ESPACIO.pdf

FRAILE PÉREZ DE MENDIGUREN, P. (2011): «Delito, represión y percepción de seguridad: la intervención territorial y el conflicto» en Oñati Socio-Legal Series, vol. 1, nº 2, 19.

FROST, A. (2011): Botany Bay: The Real Story. Collingwood, Black Inc.

FOUCAULT, M. (1963): Naissance de la clinique. Paris, PUF.

FOUCAULT, M. (1975): Surveiller et punir. Naissance de la prison. Paris, Gallimard.

GALFIONE, C. (2012): «La sociología criminal de Enrico Ferri : entre el socialismo y la intervención disciplinaria» en VII Jornadas de Sociología de la Universidad Nacional de la Plata, La Plata, 5 al 7 de diciembre de 2012. 
Disponible en http://jornadassociologia.fahce.unlp.edu.ar/actas/Galfione.pdf/at_download/file

GARCÍA SIERRA, P. (1993): «La evolución filosófica e ideológica de la Asociación Española para el Progreso de las Ciencias» en El Basilisco, Revista de filosofía, ciencias humanas, teoría de la ciencia y de la cultura, $\mathrm{n}^{\circ} 15,49-81$.

GARLAND, D. (2006): Castigo y sociedad moderna. Un estudio de teoría social. México D.F., Siglo XXI Editores. ( $1{ }^{\mathrm{a}}$ edición: 1990 Punishment and modern society. Oxford University Press).

GARRIDO, L. (1983): Manual de ciencia penitenciaria. Madrid, Edersa.

GONZALEZ GUITIÁN, L. (1985): Ramón de la Sagra: utopía y reforma penitenciaria. A Coruña, Ediciós do Castro, ensaio.

GROSSMANN, R. (1998): «Alexis de Toqueville: ses années d'aprentissage, ses doutes», en Mémoires de l'Académie nationale de Metz, 85-111.

IGNATIEFF, M. (1982): Le origini del penitenziario. Sistema carcerario e rivoluzione industriale inglese (1750-1850). Milano, Arnoldo Mondadori Editore ( $1^{\mathrm{a}}$ edición: 1978, A Just Mesure of Pain. The Penitentiary in the Industrial Revolution 1750-1850).

LARIO, D. de (2004): Al hilo del tiempo. Controles y poderes de una España imperial. Valencia, Universitat de València.

MELOSSI, D.; PAVARINI, M. (1982): Carcere et fabbrica. Alle origini del sistema penitenziario. Bologna, Società editrice il Mulino (1 ${ }^{\mathrm{a}}$ edición: 1977$)$.

PALACIO RAMOS, R (1998): «Relaciones entre la villa de Santoña y la Armada en los siglos XVII, XVIII y XIX» en Monte Buciero, $\mathrm{n}^{\circ}$ 2, 183-200.

PALACIO RAMOS, R. (2000): «Dársenas y machinas: infraestructuras y actividad pesquera en Santoña (1830-1910)» en Santoña: de los escabeches a los salazones. La transformación de una villa litoral de Cantabria (Gómez Pellón, E. edit.). Santander. Universidad de Cantabria, 11-24.

PALACIO RAMOS, R. (2001): «El ave fenix o de cómo mudó Santoña de plaza fuerte a emporio pesquero» en Monte Buciero, $\mathrm{n}^{\circ}$ 6, 63-78.

PALACIO RAMOS, R. (2004): Un presidio Ynconquistable. La fortificación de la bahía de Santoña entre los siglo XVI y XIX. Madrid. Ministerio de Defensa, Ayuntamiento de Santoña. Reseña disponible en http:/www.ub.edu/geocrit/b3w-603.htm

PALACIO RAMOS, R. (2006): «Las infraestructuras portuarias en Santoña de interés militar al despegue económico (1800-1950)» en Estudios Trasmeranos, n 3 , 91-108.

PAVARINI, M. (1983): Control y dominación. Teorías criminológicas burguesas y proyecto hegemónico. México D.F./Buenos Aires. Siglo XXI Editores ( $1^{\text {a }}$ edición en italiano: 1980).

PEREZ GARCIA, G. (2002): «La colonia penitenciaria de Villa Cisneros. Deportaciones y fugas durante la Segunda República», en Historia y Comunicación Social, vol. 7, pp. 169-186.

SALVADOR, T. (1958): Cabo de vara. Barcelona, Ediciones Destino.

SIERRA ÁLVAREZ, J. (1984): «De las utopías socialistas a las utopías patronales» en Reis: Revista española de investigaciones sociológicas, $\mathrm{n}^{\circ} 26,29-44$.

SPIERENBURG, P. (1991): The prison experience: disciplinary institutions and their inmates in early modern Europe. New Brunswick, Rutgers University Press.

WACQUANT, L. (2010): Castigar a los pobres. El gobierno neoliberal de la inseguridad social. Barcelona, Gedisa ( $1^{\text {a }}$ edición en inglés: 2009).

WOOLEN, G. (1985): «La misère de la philanthropie: Benjamin Appert à Rémelfing (184144)», en Les Cahiers Lorrains, n 2 , 145-162. 